\title{
A Double-Flipped Virtual Classroom Format for Medical Students Learning Ophthalmology: An Approach to Clinical Rotations in the Context of COVID-19
}

\author{
S. Taylor Brady, BS ${ }^{1}$ Srav Vegunta, $\mathrm{MD}^{2}$ Lenora M. Olson, $\mathrm{PhD}^{3}$ Ben J. Brintz, BS \\ Jeff H. Pettey, MD, MBA ${ }^{5}$ Griffin J. Jardine, $M D^{5 \odot}$ \\ 1 University of Utah School of Medicine, Salt Lake City, Utah \\ ${ }^{2}$ Department of Ophthalmology and Visual Sciences, Moran Eye \\ Center, Sciences University of Utah, Salt Lake City, Utah \\ ${ }^{3}$ Division of Critical Care, Department of Pediatrics, University of \\ Utah, Salt Lake City, Utah \\ ${ }^{4}$ Division of Epidemiology, Department of Internal Medicine, \\ University of Utah, Salt Lake City, Utah \\ ${ }^{5}$ Department of Ophthalmology and Visual Sciences, Moran Eye \\ Center, University of Utah, Salt Lake City, Utah \\ Address for correspondence Griffin Jardine, MD, University of Utah \\ Health, 65 Mario Capecchi Drive, Salt Lake City, UT 84132 \\ (e-mail: griffin.jardine@hsc.utah.edu). \\ J Acad Ophthalmol 2022;14:e18-e22.
}

\author{
Abstract \\ Keywords \\ - medical education \\ - flipped classroom \\ - ophthalmology \\ - COVID-19 pandemic \\ education \\ - medical students \\ - residents \\ - virtual learning \\ - online learning \\ - clinical rotation
}

Purpose The aim of this study was to assess efficacy of a virtual, double-flipped clinical rotation in ophthalmology for medical students during the coronavirus disease 2019 (COVID-19) pandemic.

Methods We instituted a virtual, reverse-classroom clinical elective for eight medical students interested in ophthalmology as a career. The course included required prework, interactive case-based discussions, and follow-up quizzes (first flip) entirely prepared and delivered by the students as teachers (second flip). After completion of the course, we surveyed students on five domains: (1) Autonomy and Leadership, (2) Self-Efficacy, (3) Impact on Career Selection, (4) Quality of Educational Experience, and (5) Clear Goals and Feedback using a Likert scale of $1-5$ ( 5 being the most positive). We also asked open-ended questions regarding the overall experience, that is, strengths, weaknesses, and future recommendations for the course. Due to the small $\mathrm{N}$ and exploratory nature of the study, no formal statistical inference was performed.

Results Seven students responded to the survey. Aggregated mean survey scores for each domain are represented in parentheses. Responses were very positive in regard to "Autonomy and Leadership" (4.5), "Impact on Career Selection" (4.1), "Quality of Educational Experience" (5.0), and "Clear Goals and Feedback" (4.4). "Self-Efficacy," which had an emphasis on ability to perform an eye exam and basic knowledge of ophthalmology, had a lower mean (3.4). The subjective responses were also very positive, but similarly alluded to the limitation of learning examination skills virtually. received

March 13, 2021

accepted after revision

October 12, 2021
Dol https://doi.org/ $10.1055 / \mathrm{s}-0041-1740327$ ISSN 2475-4757.

\footnotetext{
(c) 2022. The Author(s).

This is an open access article published by Thieme under the terms of the Creative Commons Attribution-NonDerivative-NonCommercial-License, permitting copying and reproduction so long as the original work is given appropriate credit. Contents may not be used for commercial purposes, or adapted, remixed, transformed or built upon. (https://creativecommons.org/ licenses/by-nc-nd/4.0/)

Thieme Medical Publishers, Inc., 333 Seventh Avenue, 18th Floor, New York, NY 10001, USA
} 
Conclusions A medical school clinical elective can be successfully executed in a virtual format with an emphasis on student-directed learning. The novel "doubleflipped" approach was highly rated by our small sample size. However, there remained a glaring limitation in the ability to transfer clinical skills in the virtual format. In the context of limited in-person contact due to the COVID-19 pandemic, we believe that the double-flipped, virtual format was a viable replacement for a traditional clinical rotation.

The coronavirus disease 2019 (COVID-19) pandemic and corresponding "shelter in place" mandate significantly disrupted the education of students at all levels. ${ }^{1,2}$ Students in healthcare professions have been in a particular predicament given the required hands-on experience needed to master patient-care and examination skills. For third- and fourthyear medical students, this hands-on exposure is pivotal in application of medical knowledge, doctoring patients, and selecting a residency.

In the wake of clerkship and rotation shutdowns resulting from the COVID-19 pandemic, our group instituted an online alternative to the traditional ophthalmology clerkship for students preparing to apply to an ophthalmology residency. To create an optimally engaging learning atmosphere, a novel approach was employed using a reverse or flipped classroom approach with the additional element of students as curators and teachers of content.

\section{Materials and Methods}

This project was exempt by the Institutional Review Board (IRB_00133509). Eight medical students from the University of Utah participated in the virtual elective. All eight students had expressed interest in considering ophthalmology as a career at the time of the elective. Classes were held via Zoom (San Jose, CA) videoconferencing software and were scheduled for approximately 2 hours per weekday for 2 weeks.

Before the elective was implemented, the faculty and resident instructors created a curriculum outline within Google Classroom (Mountain View, CA) for students to upload course content. The course instructors also provided materials and one zoom meeting ahead of the rotation on how to teach, with emphasis on how to select and assign pre-work, how to prepare effective PowerPoint presentations, and write highquality multiple choice test questions. ${ }^{3}$ The prework commonly included PowerPoint presentations, textbook chapters, videos, and journal articles. For in-class presentations, most students chose to teach using a case-based approach. The students were given the option of having an attending and/or resident review their materials ahead of time to optimize their presentations for accuracy and clarity.

Each day consisted of two, 1-hour presentations, allowing each student to present twice during the rotation. A resident and attending also presented to provide "modeling" examples. The first week covered the "8-Point Eye Exam," with its corresponding anatomy and basic pathology. The topics covered were visual acuity, confrontational visual fields, motility exam, pupillary exam, intraocular pressure, external eye exam, slit lamp exam, and fundus exam. The second week was organized by "Common Chief Complaints," which were diplopia, eye swelling, painful vision loss, painless monocular vision loss, painless binocular vision loss, red eye, flashes and floaters, watering eye, and eye pain without vision loss.

Each day, students and faculty provided immediate feedback to the student(s) who presented. No tests or exams were given aside from the multiple-choice questions described above. The final grade was pass/fail based on attendance and participation.

Following the conclusion of the elective, an anonymous survey was sent out to the students who had participated in the course. Eight (six male, two female) students were involved in the rotation, and seven responded to the survey at the conclusion of the rotation. The survey included 18 questions, 14 questions with Likert-scale response possibilities (1-5), and four questions with open-ended free responses. The questions were divided into five domains: (1) Autonomy and Leadership, (2) Self-Efficacy, (3) Impact on Career Selection, (4) Quality of Educational Experience, and (5) Clear Goals and Feedback.

Statistical summaries including median, interquartile range (IQR), and top two box scores (the proportion of responses in the top two most positive Likert-scale responses) were used to summarize survey responses. Histograms are provided for each question as a visual of the complete distribution of survey responses. All summaries were created using $\mathrm{R}$ version 3.6.2. ${ }^{4}$

\section{Results}

Frequency of responses by question and by student is displayed using histograms in - Fig. 1. A score of 5 was the most positive and a score of 1 was the most negative. The median, IQR, and top two box scores are shown in - Table 1.

Given the discrete nature of Likert-scale responses, the median value is included in parentheses. Within the domain of "Impact on Career Selection," the majority of students responded that they were "completely" confident that ophthalmology was the right career for them (median =5) and rated the elective as "very influential" in determining student interest in pursuing ophthalmology (4).

Within the domain of "Self-Efficacy," students rated their ability to perform an eye exam as "slightly confident" (4) but 

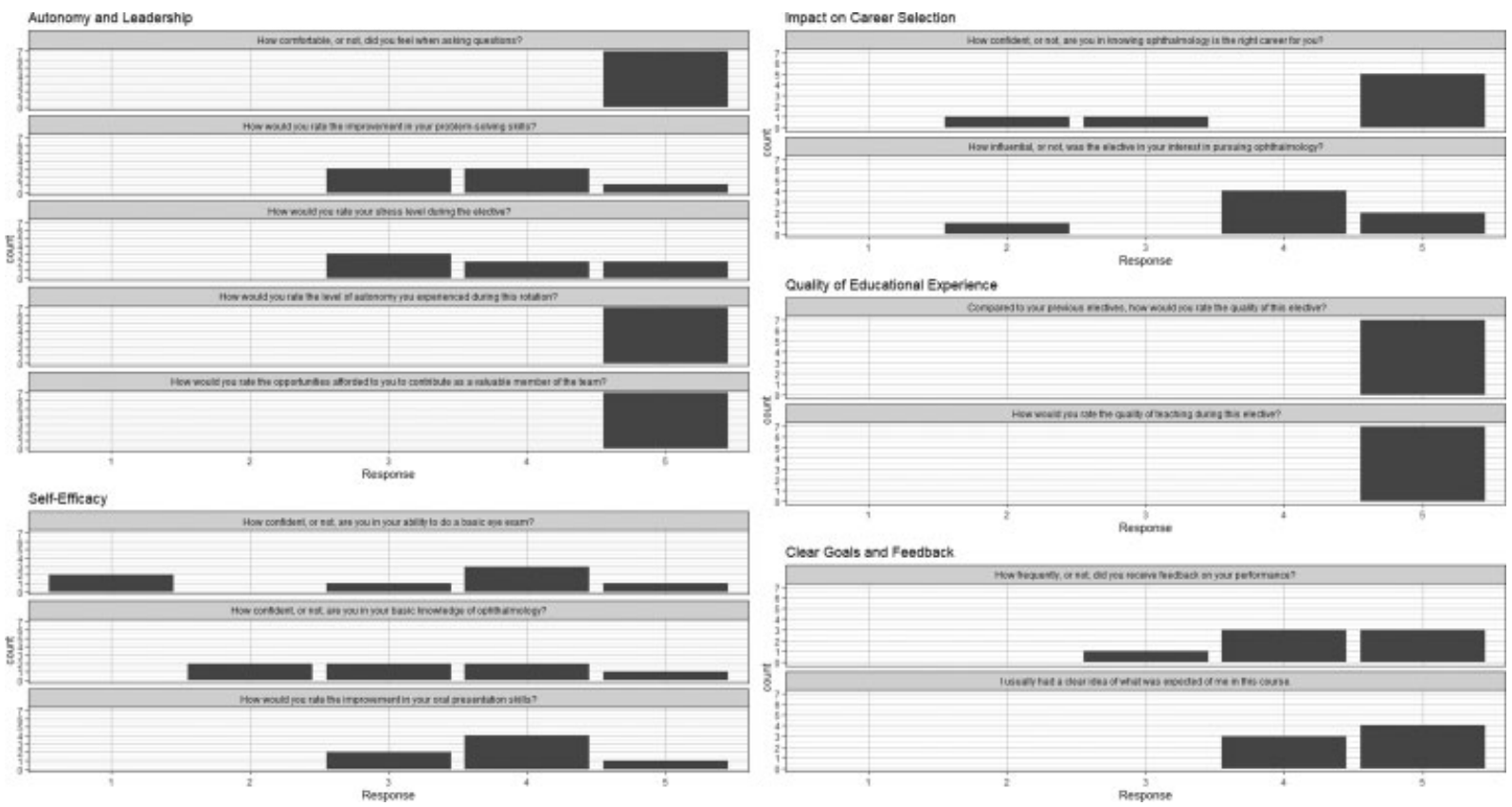

Fig. 1 Students' frequency of responses is displayed here in a histogram format organized by the five domains of survey questions asked.

Table 1 Table provides the median, IQR and top two box scores of the seven students' surveys

\begin{tabular}{|c|c|c|c|c|c|}
\hline Domain & Question & $\begin{array}{l}\text { Median } \\
\text { score (IQR) }\end{array}$ & $\begin{array}{l}\text { Top } 2 \text { box } \\
\text { frequency }\end{array}$ & $\begin{array}{l}\text { Mean } \\
\text { score }\end{array}$ & $\begin{array}{l}\text { Aggregate } \\
\text { mean }\end{array}$ \\
\hline \multirow[t]{5}{*}{$\begin{array}{l}\text { (1) Autonomy and } \\
\text { Leadership }\end{array}$} & $\begin{array}{l}\text { How comfortable, or not, did you feel when asking } \\
\text { questions? }\end{array}$ & $5(0)$ & 7 & 5.0 & \multirow[t]{5}{*}{4.5} \\
\hline & $\begin{array}{l}\text { How would you rate the improvement in your problem- } \\
\text { solving skills? }\end{array}$ & $4(1)$ & 4 & 3.7 & \\
\hline & How would you rate your stress level during the elective? & $4(1.5)$ & 4 & 3.9 & \\
\hline & $\begin{array}{l}\text { How would you rate the level of autonomy you } \\
\text { experienced during this rotation? }\end{array}$ & $5(0)$ & 7 & 5.0 & \\
\hline & $\begin{array}{l}\text { How would you rate the opportunities afforded to you to } \\
\text { contribute as a valuable member of the team? }\end{array}$ & $5(0)$ & 7 & 5.0 & \\
\hline \multirow[t]{3}{*}{ (2) Self-Efficacy } & $\begin{array}{l}\text { How confident, or not, are you in your ability to do a basic } \\
\text { eye exam? }\end{array}$ & $4(2)$ & 4 & 3.1 & \multirow[t]{3}{*}{3.4} \\
\hline & $\begin{array}{l}\text { How confident, or not, are you in your basic knowledge } \\
\text { of ophthalmology? }\end{array}$ & $3(1.5)$ & 3 & 3.3 & \\
\hline & $\begin{array}{l}\text { How would you rate the improvement in your oral } \\
\text { presentation skills? }\end{array}$ & $4(0.5)$ & 5 & 3.9 & \\
\hline \multirow[t]{2}{*}{$\begin{array}{l}\text { (3) Impact on } \\
\text { Career Selection }\end{array}$} & $\begin{array}{l}\text { How confident, or not, are you in knowing } \\
\text { ophthalmology is the right career for you? }\end{array}$ & $5(1)$ & 5 & 4.3 & \multirow[t]{2}{*}{4.1} \\
\hline & $\begin{array}{l}\text { How influential, or not, was the elective in your interest } \\
\text { in pursuing ophthalmology? }\end{array}$ & $4(0.5)$ & 6 & 4.0 & \\
\hline \multirow{2}{*}{$\begin{array}{l}\text { (4) Quality of } \\
\text { Educational } \\
\text { Experience }\end{array}$} & $\begin{array}{l}\text { Compared with your previous electives, how would you } \\
\text { rate the quality of this elective? }\end{array}$ & $5(0)$ & 7 & 5.0 & \multirow[t]{2}{*}{5.0} \\
\hline & $\begin{array}{l}\text { How would you rate the quality of teaching during this } \\
\text { elective? }\end{array}$ & $5(0)$ & 7 & 5.0 & \\
\hline \multirow[t]{2}{*}{$\begin{array}{l}\text { (5) Clear Goals and } \\
\text { Feedback }\end{array}$} & $\begin{array}{l}\text { How frequently, or not, did you receive feedback on your } \\
\text { performance? }\end{array}$ & $4(1)$ & 6 & 4.3 & \multirow[t]{2}{*}{4.4} \\
\hline & $\begin{array}{l}\text { I usually had a clear idea of what was expected of me in } \\
\text { this course. }\end{array}$ & $5(1)$ & 7 & 4.6 & \\
\hline
\end{tabular}

Abbreviation: IQR, interquartile range. 
had a relatively larger variance or IQR of 2 . The students assessed their basic knowledge of ophthalmology as "somewhat confident" (3) with an IQR of 1.5. With regard to oral presentation skills, students reported a "somewhat high" improvement overall (4).

"Quality of Educational Experience" was universally rated as "Very High" and "Very Good" across two questions regarding the quality of the elective on its own and quality of the elective versus other electives (median for both questions was 5).

The answers to the free response questions were unanimous in supporting the amount of autonomy provided for them as instructors. One such anonymous comment was, "The small-group, very interactive, student-led learning environment provided for a very engaging and stimulating learning experience. I loved how the students led the discussion, but the expert physicians provided commentary and redirection where necessary." Many of them commented on the need for in-person, hands-on experience, but their "ideal elective" universally recommended incorporating elements of the flipped-classroom model.

\section{Discussion}

The circumstances of the COVID-19 pandemic shelter-inplace forced many educational programs to adapt and innovate. Out of necessity, we designed a virtual replacement of a normally exclusively in-person clinical elective. Based on the survey results, the virtual adaptation was surprisingly effective. Even though the zoom conference was limited to two hours per day, most students reported spending several hours per day on the course materials. This included reviewing prework, reviewing the content presented that day and several hours preparing their individual topics. For comparison, these subjects are not explicitly covered in our traditional clinical rotation, but students are exposed to most of these exam techniques and topics.

The "double-flipped" approach was not without its limitations, however. A common complaint in the anonymous free response section of our survey was the lack of hands-on experience in the course. Ophthalmology involves a variety of unique techniques and tools not used in other medical specialties. Acquiring skills in the use of these techniques and tools is one of the primary goals of ophthalmology rotations. Students reported an average confidence in their ability to perform a basic eye exam after the course, even though this topic was covered extensively. The state of the COVID-19 pandemic dictated that in-person experiences would have to be limited during this rotation. However, our experience was so positive that we concluded future courses would benefit from a hybrid model with both double-flipped teaching and in-person sessions where hands-on physical exam skills could be taught.

The idea of enhancing student learning through "active"-rather than "passive"-learning has been around for decades and was popularized by Alison King in, From Sage on the Stage to Guide on the Side..$^{5}$ In her work, King suggests that learning should be viewed as a process by which knowledge is transferred from one person to another via "reconstruction," that is, “...students use their own existing knowledge and prior experience to help them understand the new material."

From an increased use of active learning modalities in education settings, the flipped-classroom was born. Coined by J. Wesley Baker in $2000,{ }^{6}$ the "flipped classroom" utilizes interactive learning with the goals of increasing student involvement and, therefore, student retention. Many flipped-classroom formats exist with educators using a wide range of techniques including assigned prework, hands-on learning, group discussion and group work, mentor/mentee dynamics, and many other methods.

This format has been studied in head-to-head comparisons in medical education with traditional, lecture-based teaching. ${ }^{7}$ Tan et al incorporated interactive cases, didactics, self-learning modules, quizzes, and examinations into their flipped-classroom radiology elective for fourth-year medical students at University of California Riverside. ${ }^{8}$ They showed objective increases in student scores as well as increased subjective knowledge increases. There are other studies regarding flipped classroom models in medical education but none in which student-led teaching predominates. $^{9-11}$

Widely accessible technology opened the door to new modalities of teaching in the midst of the COVID-19 pandemic. With the initial "Shelter-in-place" and subsequent fluctuations in case numbers and hospitalizations, educational systems have had to adapt and readapt to a dynamic situation. At times, in-person meeting has been drastically reduced or suddenly closed. Within medical schools, this has been particularly complicated for third- and fourth-year students who have had to miss out on valuable clinical rotations.

Obtaining a more rigorous statistical analysis and evaluation of our teaching approach would require larger numbers and a comparative arm of traditional teaching. However, one of our concerns with using this technique in a large group setting is the demanding nature of participating as studentteachers. Our format caters better to highly motivated students with unique interest in the subject matter in a smallgroup setting. We were fortunate to have students already interested in ophthalmology participate in our virtual elective-which we also acknowledge may have biased our survey results despite their anonymity. It is unclear if the same format would have similar success in a full class with a broader range of career interests.

Our study was limited by a small sample size of students. Generating any statistically significant data analysis was outside of our scope. But the main purpose of our study was to report an alternative approach necessitated by a confluence of factors to traditional clinical rotations and electives. We do not advocate for replacement of in-person learning with virtual learning in the clinical realm; rather, we report the success of an interactive, highly participatory approach to virtual learning as a potential supplement or temporary substitute to the required hands-on experience in healthcare education. 
e22 A Double-Flipped Virtual Classroom Format for Medical Students Learning Ophthalmology Brady et al.

\section{Conclusion}

The COVID-19 pandemic and resultant shutdowns have brought unprecedented restrictions and changes to medical education. We have presented a virtual alternative to a clinical medical student ophthalmology rotation with a novel approach that enhances student engagement. The course was overall rated very favorably, but lacked the transfer of physical exam skills, a valuable and necessary part of medical training. However, the depth of knowledge, exposure to the specialty, and teaching opportunities through the double-flipped style may have certain advantages over the purely clinical rotation format.

\section{Funding}

This investigation was supported by the University of Utah Study Design and Biostatistics Center, with funding in part from the National Center for Research Resources and the National Center for Advancing Translational Sciences, National Institutes of Health, through Grant 8UL1TR000105 (formerly UL1RR025764).

\section{Conflict of Interest}

None.

\section{References}

1 Ahmed H, Allaf M, Elghazaly H. COVID-19 and medical education. Lancet Infect Dis 2020;20(07):777-778
2 Dedeilia A, Sotiropoulos MG, Hanrahan JG, Janga D, Dedeilias P, Sideris M. Medical and surgical education challenges and innovations in the COVID-19 3ra: a systematic review. In Vivo 2020;34 (3, Suppl):1603-1611

3 Coughlin PA, Featherstone CR. How to write a high quality multiple choice question (MCQ): a guide for clinicians. Eur J Vasc Endovasc Surg 2017;54(05):654-658

4 R Core Team (2019) R: A Language and Environment for Statistical Computing. R Foundation for Statistical Computing, Vienna, Austria. Accessed October 25, 2021 at https://www.R-project.org/

5 King A. From Sage on the Stage to Guide on the Side. Coll Teach 1993;41(01):30-35

6 Tang F, Chen C, Zhu Y, et al: Comparison between flipped classroom and lecture-based classroom in ophthalmology clerkship. Med Educ Online 2017;22:1395679

7 Tang F, Chen C, Zhu Y, et al. Comparison between flipped classroom and lecture-based classroom in ophthalmology clerkship. Med Educ Online 2017;22(01):1395679

8 Tan N, Bavadian N, Lyons P, Lochhead J, Alexander A. Flipped classroom approach to teaching a radiology medical student clerkship. J Am Coll Radiol 2018;15(12):1768-1770

9 Morgan H, McLean K, Chapman C, Fitzgerald J, Yousuf A, Hammoud M. The flipped classroom for medical students. Clin Teach 2015;12(03):155-160

10 Durfee SM, Goldenson RP, Gill RR, Rincon SP, Flower E, Avery LL. Medical student education roadblock due to COVID-19: virtual radiology core clerkship to the rescue. Acad Radiol 2020;27(10): 1461-1466

11 Park KH, Park KH, Chae SJ. Experiences of medical teachers in flipped learning for medical students: a phenomenological study. Korean J Med Educ 2018;30(02):91-100 